\title{
Educating Patients by Providing Timely Information Using Smartphone and Tablet Apps: Systematic Review
}

Thomas Timmers ${ }^{1,2}$, MSc; Loes Janssen ${ }^{3}$, PhD; Rudolf B Kool ${ }^{1}$, MD, PhD; Jan AM Kremer ${ }^{1}$, MD, PhD

${ }^{1}$ IQ healthcare, Radboud Institute for Health Sciences, Radboud University Medical Center, Nijmegen, Netherlands

${ }^{2}$ Interactive Studios, Rosmalen, Netherlands

${ }^{3}$ Máxima Medical Center, Veldhoven, Netherlands

Corresponding Author:

Thomas Timmers, MSc

IQ healthcare

Radboud Institute for Health Sciences

Radboud University Medical Center

Geert Grooteplein Zuid 10

Nijmegen, 6525 GA

Netherlands

Phone: 31736446069

Email: thomas.timmers@ radboudumc.nl

\begin{abstract}
Background: Patient education is a crucial element within health care. It is a known predictor for increased engagement in shared decision making, improved medication and treatment adherence, higher levels of satisfaction, and even better treatment outcomes. Unfortunately, often patients only remember a very limited amount of medical information. An important reason is that most patients are simply not capable of processing large amounts of new medical information in a short time. Apps for smartphones and tablets have the potential to actively educate patients by providing them with timely information through the use of push notifications.
\end{abstract}

Objective: The objective of this systematic review is to provide an overview of the effects of using smartphone and tablet apps to educate patients with timely education. Within this review, we focused on patients that receive their care in a hospital setting. We assessed the effects of the interventions on outcomes, such as patients' knowledge about their illness and treatment, adherence to treatment instructions and to medication usage, and satisfaction with the care they received.

Methods: A comprehensive search of MEDLINE (Medical Literature Analysis and Retrieval System Online), Embase, CINAHL (Cumulative Index to Nursing and Allied Health Literature), and Web of Science was conducted. Randomized controlled trials (RCTs) published between January 2015 and November 2019 were eligible for inclusion. Two reviewers independently searched and screened articles, assessed study quality and risk of bias, and extracted the data. Due to the heterogeneity of populations, interventions, and outcomes, a meta-analysis was not deemed appropriate. Instead, a narrative synthesis is presented.

Results: A total of 21 RCTs with 4106 participants were included. Compared to usual care, overall effectiveness of the interventions was demonstrated in $69 \%$ of the outcomes. Effectiveness increased to $82 \%$ when the intervention had a duration shorter than one month and increased to $78 \%$ when the intervention provided at least one push notification per week. The interventions showed the highest effects on satisfaction with information, adherence to treatment instructions and to medication usage, clinical outcomes, and knowledge.

Conclusions: This review demonstrates that educating patients with timely medical information through their smartphones or tablets improves their levels of knowledge, medication or treatment adherence, satisfaction, and clinical outcomes, as well as having a positive effect on health care economics. These effects are most pronounced in interventions with a short duration (ie, less than a month) and with a high frequency of messages to patients (ie, once per week or more). With the knowledge that patient education is a predictor for improved outcomes and the fact that patients have obvious difficulties processing large amounts of new medical information, we suggest incorporating the delivery of timely information through smartphone and tablet apps within current medical practices.

(J Med Internet Res 2020;22(4):e17342) doi: 10.2196/17342 


\section{KEYWORDS}

patient education; push notification; self-management; eHealth; timely information; timely education; smartphone; tablet computer; self-care; mobile phone

\section{Introduction}

Patient education is a crucial element within health care. Health care professionals provide patients with information about the origins of complaints, treatment options, prognosis, how to prepare for treatment, or how to manage one's health during the recovery phase. Health care professionals educate their patients because knowledge is a known predictor for increased engagement in shared decision making, improved medication and treatment adherence, higher levels of satisfaction, and better outcomes [1,2].

Unfortunately, patients often only remember a limited amount of the medical information they receive. Many different factors contribute to this. Some of these factors are related to the health care professional, such as using jargon or communicating in a passive way. Other factors are related to the patient, such as age, learning style, and stress [3]. Another important reason is the fact that most patients are simply not capable of processing large amounts of new medical information in a short amount of time [4].

During the last decade, smartphones, tablets, and apps have become commonplace in our society. These innovations offer many new opportunities within health care, such as optimizing the process of patient education. Apps, for example, allow patients to look at medical information as often as they like, at any place, and at any time. The information is comprehensive and different modes of information delivery and interaction are available. Furthermore, push notifications allow health care providers to actively educate patients with timely information, which, in this review, is defined as providing patients with small pieces of information at the time that these are actually relevant to them.

Although interventions like these appear to have much potential in allowing patients to better understand and to remember medical information, an overview of all available evidence on the effectiveness of these technologies has thus far not been published. The objective of this systematic review is to provide an overview of the effectiveness of educating patients by providing timely information using smartphone and tablet apps. With this systematic review, we focused on patients that receive care in a hospital setting rather than in primary care. We have chosen to do so since projects in primary care have already demonstrated effectiveness of electronic health (eHealth) apps, but these primarily focused on chronically ill patients from a population perspective and on telemonitoring services from an intervention perspective.

In this paper, we assess the effects that these interventions have on outcomes, such as patients' knowledge about their illness and treatment options, adherence to medication or instructions, and satisfaction with the information or the care they received.

\section{Methods}

\section{Search Strategy and Data Sources}

To identify relevant studies, we used a two-step strategy. First, we conducted a preliminary search in PubMed to identify key articles, relevant keywords, and Medical Subject Headings (MeSH) terms. The second step was to have the search strategy be peer reviewed by an information specialist from the Radboud academic medical center's medical library. Multimedia Appendix 1 shows the search strategy for the final search. We comprehensively searched the following databases: MEDLINE (Medical Literature Analysis and Retrieval System Online) (Ovid); Embase (Elsevier); CINAHL (Cumulative Index to Nursing and Allied Health Literature) (EBSCO); and Web of Science. Relevant systematic reviews were also assessed for eligible articles. In order to compare the effectiveness of interventions, we preferred to only include randomized controlled trials (RCTs). Since we were unsure about the number and quality of RCTs, our primary search also included cohort and quasi-experimental studies. After assessing the number and quality of RCTs, we decided to only include these in the review. Reporting was done in accordance with the PRISMA (Preferred Reporting Items for Systematic Reviews and Meta-Analyses) guidelines [5].

Based on the results of our preliminary search, we deliberately limited our search to articles published between January 1, 2015, and November 1, 2019, as the interventions described before this period did not meet the eligibility criteria or could no longer be repeated since the technique was outdated or no longer available. We searched for papers in English and looked at reference lists of included studies to optimize our search.

\section{Eligibility Criteria}

RCTs were included if they met a number of eligibility criteria: (1) interventions had a focus on patient education through a smartphone or tablet app, used in a hospital setting; (2) interventions had to use push notifications to actively notify patients about newly available information in the app; and (3) the intervention had to be available for multiple days.

We excluded trials that focused solely on the acceptance or feasibility of technology, content or design of the intervention, availability in app stores, telemedicine (ie, remote care), websites or online platforms, or trials that only described the usage of an SMS. Furthermore, articles focusing on data collection, security, behavior or characteristics of patients, and health care professionals were excluded, as were study protocols. Studies were not excluded on the basis of sociodemographic characteristics of patients, such as age, gender, ethnicity, or any other related characteristic.

\section{Data Selection, Extraction, and Management}

The search results from different electronic databases were combined within a single Endnote library, version 8.2 (Clarivate Analytics), and duplicates were removed. Two reviewers (TT 
and $\mathrm{LJ}$ ) independently screened titles and abstracts to identify studies that potentially met the inclusion criteria. The full text of these articles was retrieved and read. Two review authors (TT and LJ) independently assessed these articles against the eligibility criteria and extracted the data from the included studies using a structured data extraction form. Disagreements were resolved through discussion and, if necessary, a third reviewer (RBK) was consulted. We extracted information about the patient population, outcomes, interventions, controls, results, and outcome measures.

\section{Assessment of Risk of Bias}

Two reviewers (TT and LJ) independently assessed the risk of bias of included RCTs using the Cochrane Collaboration's risk of bias tool [6]. Judgements concerning the risk of bias for each study were classified as high, some concerns, or low.

\section{Data Synthesis}

Included studies were insufficiently homogenous in terms of patient population, outcomes, and type of intervention. The decision not to perform a meta-analysis was made as a consensus by all authors. For any outcome that was investigated in three or more studies, we present a narrative synthesis of results. In order to compare the effects of the different interventions over the different studies, a standardized mean difference (SMD) is reported, including the $95 \% \mathrm{CI}$ for the effect. SMD is reported only when results are normally distributed and mean and SD are available. The magnitude of the effect is interpreted according to Cohen's guidelines: small (SMD is 0.2 or lower), medium (SMD is between 0.2 and 0.8 ), or large (SMD is 0.8 or higher) [7].

Furthermore, we created a narrative synthesis of overall results per outcome in relation to the duration of the intervention or the frequency with which messages were sent to the patient. Therefore, the duration of the intervention was subdivided into short $(<1$ month) and long ( $\geq 1$ month). The frequency of messaging was subdivided into high $(>1$ message per week) or low ( $\leq 1$ message per week). The relative effectiveness was calculated by dividing the total number of participants in studies that demonstrated an effect for the outcome by the total number of participants in studies linked to the outcome. Finally, a weighted overall effect was calculated summarizing all outcomes, specified for the duration of the intervention and the frequency of messages.

\section{Results}

\section{Overview}

Our searches yielded a total of 5497 articles from which 2041 unique articles were derived. After screening titles and abstracts, 1970 records were excluded. A total of 71 articles were assessed for eligibility by full-text screening. A total of 50 articles were excluded after full-text reading because of study type (ie, cohort, quasi-experimental, or other) or because the intervention used did not actually deliver timely education. In total, 21 RCTs were included in the review, including 4106 participants (see Figure 1). Sample sizes ranged from 34 participants [8] to 650 participants [9].

Figure 1. PRISMA (Preferred Reported Items for Systematic Reviews and Meta-Analyses) flowchart. RCT: randomized controlled trial.

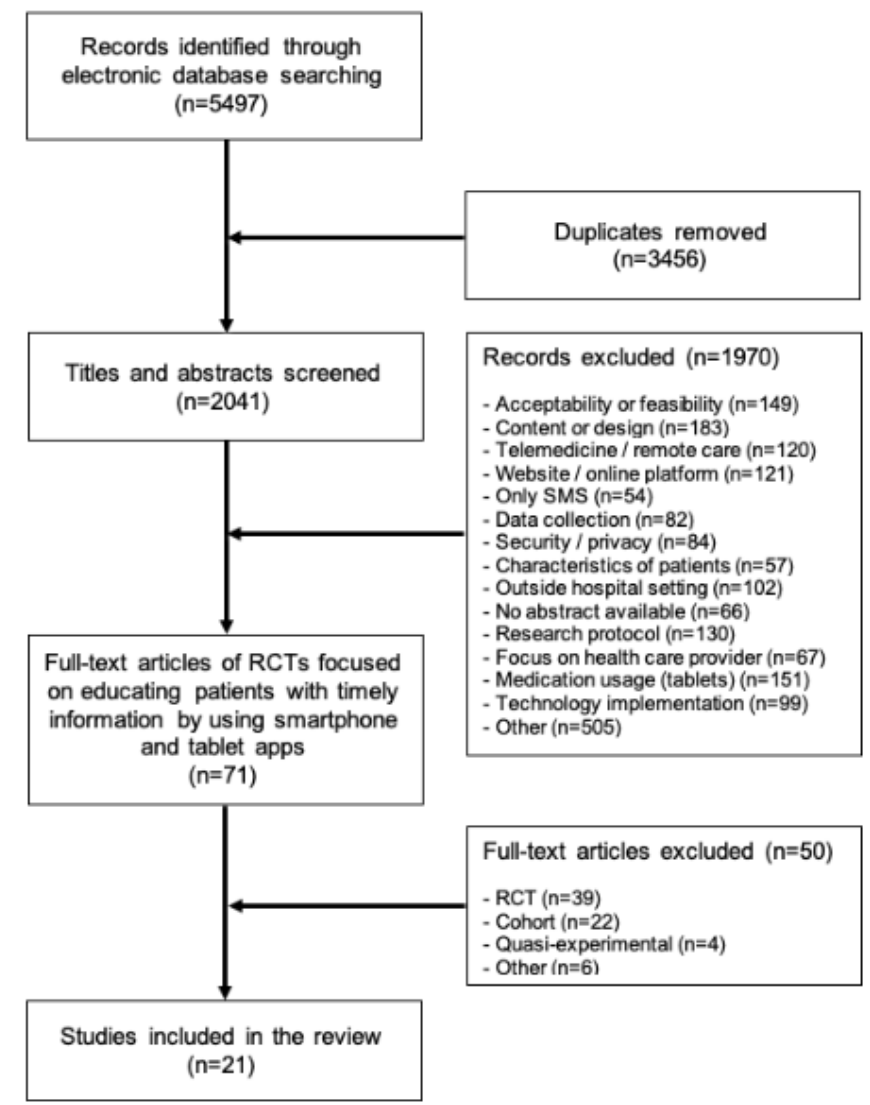




\section{Included Studies: Study Designs and Populations}

Nine studies were conducted in Europe [10-18], four studies in North America [8,19-21], five studies in Asia [9,22-27], and one study in Africa [28]. In total, 4106 patients participated in the studies. Studies were divided over many different medical departments: gastroenterology [9,18,22,24,28], orthopedics $[10,12,13]$, cardiology $[17,20,25,26]$, oncology [21], surgery $[11,19,23]$, urology [16], internal medicine [27], sports medicine [14], pulmonary disease [8], and neurology [15]. Six studies used a social media platform as the medium for the intervention [9,22-24,26,27]. Eight studies used apps that were already commercially available $[10,12-14,16,17,19,20]$ and five studies used apps that were developed specifically for the study $[8,18,21,25,28]$. A total of five interventions that were used provided the possibility to interact with a health care provider [9,22,26-28].
Two studies included detailed information about the content and timing of notifications used in the intervention $[10,17]$ and eight provided some details or images $[9,12,13,15,21,22,25,28]$. Regarding the phase of the treatment in which the study was conducted, seven studies focused on the period before the start of the treatment [9,12,18,21,22,24,28], 12 studies focused on the period after the start of the treatment [8,10,11,13-16,19,20,25-27], and one focused on both [23].

Details of the population, type of intervention, outcomes, and mean age of participants are presented in Table 1. The details of the interventions used, their duration, phase of the treatment, and frequency of notifying patients are presented in Table 2. An overview of all the measurement instruments used per study to assess these outcomes can be found in Multimedia Appendix 2 . 
Table 1. Details of the publications, interventions, outcomes, and populations.

\begin{tabular}{|c|c|c|c|c|c|c|}
\hline Study & Year & Country & Department & Population (n) & $\begin{array}{l}\text { Age (years), } \\
\text { mean }\end{array}$ & Outcomes \\
\hline Wang [22] & 2019 & China & Gastroenterology & Colonoscopy (392) & 52 & $\begin{array}{l}\text { Bowel preparation adherence, quality of } \\
\text { preparation, adenoma detection, and satis- } \\
\text { faction }\end{array}$ \\
\hline Timmers [10] & 2019 & Netherlands & Orthopedics & Knee replacement (212) & 65 & $\begin{array}{l}\text { Pain, QoL }{ }^{\mathrm{a}} \text {, physical functioning, satisfac- } \\
\text { tion, and health care consumption }\end{array}$ \\
\hline Mata [19] & 2019 & Canada & Surgery & Colorectal surgery (97) & 60 & $\begin{array}{l}\text { Recovery protocol adherence, length of stay, } \\
\text { complications, and satisfaction }\end{array}$ \\
\hline $\mathrm{Li}[23]$ & 2019 & China & Surgery & $\begin{array}{l}\text { Pediatric day-care } \\
\text { surgery }(127)\end{array}$ & $4^{b}$ & $\begin{array}{l}\text { Quality of recovery, satisfaction, and time } \\
\text { consumption during follow-up }\end{array}$ \\
\hline Jeon [24] & 2019 & South Korea & Gastroenterology & Colonoscopy (281) & 48 & $\begin{array}{l}\text { Bowel preparation adherence, quality of } \\
\text { preparation, and adenoma detection }\end{array}$ \\
\hline Van der Meij [11] & 2018 & Netherlands & Surgery & $\begin{array}{l}\text { Abdominal surgery } \\
(344)\end{array}$ & 52 & $\begin{array}{l}\text { Return to work, first return to normal activ- } \\
\text { ity, physical functioning, QoL, and satisfac- } \\
\text { tion }\end{array}$ \\
\hline Timmers [12] & 2018 & Netherlands & Orthopedics & Knee replacement (213) & 62 & $\begin{array}{l}\text { Knowledge, mobile device proficiency, } \\
\text { treatment chosen, and satisfaction }\end{array}$ \\
\hline $\begin{array}{l}\text { Najafi Ghezeljeh } \\
\text { [26] }\end{array}$ & 2018 & Iran & Cardiology & Hypertension (100) & 65 & Hypertension self-management \\
\hline Hardt [13] & 2018 & Germany & Orthopedics & Knee replacement (60) & 65 & $\begin{array}{l}\text { Range of motion, pain, and physical func- } \\
\text { tioning }\end{array}$ \\
\hline Alanzi [27] & 2018 & Saudi Arabia & Internal medicine & Diabetes mellitus (92) & $41^{\mathrm{c}}$ & Knowledge and self-efficacy \\
\hline Widmer [20] & 2017 & United States & Cardiology & $\begin{array}{l}\text { Cardiac rehabilitation } \\
(80)\end{array}$ & 64 & $\begin{array}{l}\text { In-person hospital visits, clinical values, } \\
\text { QoL, and mood }\end{array}$ \\
\hline Asklund [16] & 2017 & Sweden & Urology & $\begin{array}{l}\text { Stress urinary inconti- } \\
\text { nence }(123)\end{array}$ & 45 & Symptom severity and QoL \\
\hline Sharara [28] & 2017 & Lebanon & Gastroenterology & Colonoscopy (160) & 53 & $\begin{array}{l}\text { Bowel preparation adherence, quality of } \\
\text { preparation, and satisfaction }\end{array}$ \\
\hline Perry [8] & 2017 & United States & $\begin{array}{l}\text { Pulmonary dis- } \\
\text { ease }\end{array}$ & Asthma (34) & 15 & Asthma control and expiratory volume \\
\hline Lee [21] & 2017 & United States & Oncology & Breast cancer (120) & 52 & $\begin{array}{l}\text { Knowledge, readiness for mammography, } \\
\text { and satisfaction }\end{array}$ \\
\hline $\begin{array}{l}\text { Lakshminarayana } \\
{[15]}\end{array}$ & 2017 & $\begin{array}{l}\text { United King- } \\
\text { dom }\end{array}$ & Neurology & Parkinson disease (158) & 60 & $\begin{array}{l}\text { Medication adherence, QoL, quality of } \\
\text { consultation, anxiety and depression, and } \\
\text { beliefs about medication }\end{array}$ \\
\hline Guo [25] & 2017 & China & Cardiology & Atrial fibrillation (209) & 68 & $\begin{array}{l}\text { Knowledge, QoL, adherence, and satisfac- } \\
\text { tion }\end{array}$ \\
\hline Van Reijnen [14] & 2017 & Netherlands & Sports medicine & Ankle trauma (220) & 38 & $\begin{array}{l}\text { Incidence of ankle sprains, residual pain, } \\
\text { and ankle disability }\end{array}$ \\
\hline Kang [9] & 2016 & China & Gastroenterology & Colonoscopy (650) & 45 & $\begin{array}{l}\text { Bowel preparation adherence and compli- } \\
\text { ance with instructions }\end{array}$ \\
\hline Johnston [17] & 2016 & Sweden & Cardiology & $\begin{array}{l}\text { Myocardial infarction } \\
\text { (174) }\end{array}$ & 57 & $\begin{array}{l}\text { Medication adherence, satisfaction, and } \\
\text { QoL }\end{array}$ \\
\hline $\begin{array}{l}\text { Lorenzo-Zuniga } \\
{[18]}\end{array}$ & 2015 & Spain & Gastroenterology & Colonoscopy (260) & 50 & $\begin{array}{l}\text { Bowel preparation adherence and satisfac- } \\
\text { tion }\end{array}$ \\
\hline
\end{tabular}

${ }^{\mathrm{a} Q o L:}$ quality of life.

${ }^{\mathrm{b}} \mathrm{Age}$ of the children who underwent surgery. In the study, their parents (age not mentioned) used the app and provided the data.

${ }^{\mathrm{c}}$ Study only reports that $75 \%$ of the participants were 41 years or older. 
Table 2. Details and duration of the interventions used, frequency of notifying patients, and treatment phase.

\begin{tabular}{|c|c|c|c|c|c|c|}
\hline Study & Year & Country & Intervention and control & Duration & Notification frequency & Treatment phase $\mathrm{a}^{\mathrm{a}}$ \\
\hline Wang [22] & 2019 & China & $\begin{array}{l}\text { Dietary preparation through the WeChat plat- } \\
\text { form in the days before colonoscopy, as well } \\
\text { as timing and usage of the bowel preparation } \\
\text { solution; possibility to ask questions as well } \\
\text { Control: Standard written information }\end{array}$ & 3 days & Daily & Pre \\
\hline \multirow[t]{2}{*}{ Timmers [10] } & 2019 & Netherlands & $\begin{array}{l}\text { Day-to-day information and videos through an } \\
\text { app on pain, wound care, physiotherapy exer- } \\
\text { cises, medication usage, and self-care in the } \\
\text { early postoperative phase after total knee re- } \\
\text { placement }\end{array}$ & 28 days & Daily & Post \\
\hline & & & $\begin{array}{l}\text { Control: Simplified version of the app with } \\
\text { only basic information }\end{array}$ & & & \\
\hline \multirow[t]{2}{*}{ Mata [19] } & 2019 & Canada & $\begin{array}{l}\text { Recovery targets and educational information } \\
\text { through an app on how to achieve them in the } \\
\text { first days after surgery }\end{array}$ & 2-4 days & Daily & Post \\
\hline & & & Control: Standard written instructions & & & \\
\hline \multirow[t]{2}{*}{ Li [23] } & 2019 & China & $\begin{array}{l}\text { Recovery education through the WeChat plat- } \\
\text { form in the days before and after surgery }\end{array}$ & 2-4 days & Daily & Pre/post \\
\hline & & & Control: Telephone call by nursing staff & & & \\
\hline \multirow[t]{2}{*}{ Jeon [24] } & 2019 & South Korea & $\begin{array}{l}\text { Self-management education through the } \\
\text { WeChat platform in the days before } \\
\text { colonoscopy by using videos }\end{array}$ & 3 days & Daily & Pre \\
\hline & & & Control: Standard written information & & & \\
\hline \multirow[t]{2}{*}{$\begin{array}{l}\text { Van der Meij } \\
{[11]}\end{array}$} & 2018 & Netherlands & $\begin{array}{l}\text { Personalized eHealth }{ }^{\mathrm{b}} \text { program through an app } \\
\text { for patients undergoing abdominal surgery }\end{array}$ & 3 months & Weekly & Post \\
\hline & & & $\begin{array}{l}\text { Control: Placebo website with standard recov- } \\
\text { ery advice }\end{array}$ & & & \\
\hline \multirow[t]{2}{*}{ Timmers [12] } & 2018 & Netherlands & $\begin{array}{l}\text { Subdivided and interactive information through } \\
\text { an app in the week prior to the consultation } \\
\text { with an orthopedic surgeon because of possible } \\
\text { knee osteoarthritis }\end{array}$ & 7 days & Daily & Pre \\
\hline & & & Control: Standard information on website & & & \\
\hline \multirow[t]{2}{*}{$\begin{array}{l}\text { Najafi Ghezel- } \\
\text { jeh [26] }\end{array}$} & 2018 & Iran & $\begin{array}{l}\text { Self-management education through the Tele- } \\
\text { gram platform in the weeks after hospitaliza- } \\
\text { tion }\end{array}$ & 6 weeks & Weekly & Post \\
\hline & & & Control: Standard written information & & & \\
\hline \multirow[t]{2}{*}{ Hardt [13] } & 2018 & Germany & $\begin{array}{l}\text { Postoperatively app-based, feedback-con- } \\
\text { trolled, active muscle training program }\end{array}$ & 4 days & Daily & Post \\
\hline & & & Control: Standard physiotherapy sessions & & & \\
\hline \multirow[t]{2}{*}{ Alanzi [27] } & 2018 & Saudi Arabia & $\begin{array}{l}\text { Diabetes mellitus education through the } \\
\text { WhatsApp platform (eg, signs and symptoms, } \\
\text { diet, and exercises) }\end{array}$ & 8 weeks & Weekly & Post \\
\hline & & & Control: Standard written information & & & \\
\hline \multirow[t]{2}{*}{ Widmer [20] } & 2017 & United States & $\begin{array}{l}\text { Reporting of dietary and exercise habits } \\
\text { through an app, as well as educational informa- } \\
\text { tion on lifestyle during cardiac rehabilitation }\end{array}$ & 3 months & Occasionally & Post \\
\hline & & & Control: Web-based platform & & & \\
\hline \multirow[t]{2}{*}{ Asklund [16] } & 2017 & Sweden & $\begin{array}{l}\text { Treatment program for pelvic floor muscles } \\
\text { and information about stress urinary inconti- } \\
\text { nence and lifestyle through an app }\end{array}$ & 3 months & Daily & Post \\
\hline & & & Control: Standard written instructions & & & \\
\hline \multirow[t]{2}{*}{ Sharara [28] } & 2017 & Lebanon & $\begin{array}{l}\text { Dietary preparation through an app in the days } \\
\text { before colonoscopy, as well as timing and us- } \\
\text { age of the bowel preparation solution }\end{array}$ & 4 days & Daily & Pre \\
\hline & & & Control: Standard written instructions & & & \\
\hline
\end{tabular}




\begin{tabular}{|c|c|c|c|c|c|c|}
\hline Study & Year & Country & Intervention and control & Duration & Notification frequency & Treatment phase $^{\mathrm{a}}$ \\
\hline Perry [8] & 2017 & United States & $\begin{array}{l}\text { Education on medication usage and peak flow } \\
\text { or asthma logging through an app } \\
\text { Control: Standard written instructions }\end{array}$ & 6 months & Occasionally & Post \\
\hline Lee [21] & 2017 & United States & $\begin{array}{l}\text { Personal, tailored multimedia messages } \\
\text { through an app to prepare women for breast } \\
\text { cancer screening } \\
\text { Control: Standard written instructions }\end{array}$ & 7 days & Daily & Pre \\
\hline $\begin{array}{l}\text { Lakshmi- } \\
\text { narayana [15] }\end{array}$ & 2017 & $\begin{array}{l}\text { United King- } \\
\text { dom }\end{array}$ & $\begin{array}{l}\text { Reminding patients about medication usage, } \\
\text { tracking of self-management skills, and educat- } \\
\text { ing patients about Parkinson disease through } \\
\text { an app } \\
\text { Control: Standard written instructions }\end{array}$ & 4 months & Occasionally & Post \\
\hline Guo [25] & 2017 & China & $\begin{array}{l}\text { Educational program about atrial fibrillation } \\
\text { and how to self-manage at home } \\
\text { Control: Standard written instructions }\end{array}$ & 3 months & Occasionally & Post \\
\hline $\begin{array}{l}\text { Van Reijnen } \\
{[14]}\end{array}$ & 2017 & Netherlands & $\begin{array}{l}\text { Neuromuscular training program through an } \\
\text { app for athletes who suffered a sprained ankle } \\
\text { Control: Standard written instructions }\end{array}$ & 2 months & Occasionally & Post \\
\hline Kang [9] & 2016 & China & $\begin{array}{l}\text { Dietary preparation through the WeChat plat- } \\
\text { form in the days before colonoscopy, as well } \\
\text { as timing and usage of the bowel preparation } \\
\text { solution; possibility to ask questions as well } \\
\text { Control: Standard written instructions }\end{array}$ & 4 days & Daily & Pre \\
\hline Johnston [17] & 2016 & Sweden & $\begin{array}{l}\text { Educational messages based on the data pa- } \\
\text { tients had registered about their medication } \\
\text { usage } \\
\text { Control: Simplified version of the app with } \\
\text { only basic information }\end{array}$ & 6 months & Weekly & Post \\
\hline $\begin{array}{l}\text { Lorenzo-Zuni- } \\
\text { ga [18] }\end{array}$ & 2015 & Spain & $\begin{array}{l}\text { Dietary preparation through an app in the days } \\
\text { before colonoscopy, as well as timing and us- } \\
\text { age of the bowel preparation solution } \\
\text { Control: Standard written instructions }\end{array}$ & 4 days & Daily & Pre \\
\hline
\end{tabular}

${ }^{\mathrm{a}}$ Pre: before the start of the treatment; post: after the start of the treatment.

$\mathrm{b}$ eHealth: electronic health.

\section{Risk of Bias of Included Studies}

All 21 included studies were assessed for risk of bias in the following domains: selection of the reported result, measurement of the outcome, missing outcome data, deviations from intended interventions, and randomization process. The levels of risk-low, some concerns, or high—per study, per domain are presented in Figure 2. An overview of the percentage of studies related to the level of risk and domain of bias is presented in Figure 3. 
Figure 2. Level of risk of bias, per study, per domain.

\begin{tabular}{|c|c|c|c|c|c|c|c|}
\hline Study & 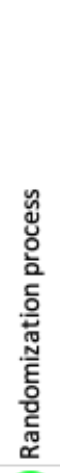 & 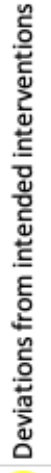 & 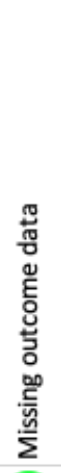 & 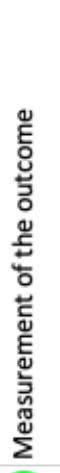 & 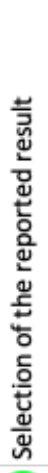 & $\begin{array}{l}\overline{\bar{\pi}} \\
\text { वेँ } \\
\text { ठ }\end{array}$ & \\
\hline Wang, 2019 & + & ? & + & + & & & Low risk \\
\hline Timmers, 2019 & & & 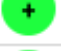 & & & & Some concerns \\
\hline Mata, 2019 & & $?$ & & + & & & High risk \\
\hline Li, 2019 & $?$ & $?$ & & $?$ & $?$ & & \\
\hline Jeon, 2019 & & $?$ & & + & $?$ & & \\
\hline Van der Meij, 2018 & & & & T & & & \\
\hline Timmers, 2018 & & & & $?$ & $?$ & & \\
\hline Najafi Ghezeljeh, 201 & & $?$ & & & & & \\
\hline Hardt, 2018 & & $?$ & & + & $?$ & & \\
\hline Alanzi, 2018 & & $?$ & & + & $?$ & & \\
\hline Widmer, 2017 & & & & $?$ & & & \\
\hline Asklund, 2017 & & ? & & & & & \\
\hline Sharara, 2017 & & & & & & & \\
\hline Perry, 2017 & & & & + & & & \\
\hline Lee, 2017 & & & & + & & & \\
\hline Lakshminarayana, 201 & & & & ? & & & \\
\hline Guo, 2017 & & & & 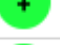 & & & \\
\hline Van Reijen, 2017 & & ? & & & & & \\
\hline Kang, 2016 & & ? & & $?$ & & & \\
\hline Johnston, 2016 & & & & + & & & \\
\hline Lorenzo-Zuniga, 2015 & & 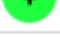 & & 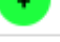 & & & \\
\hline
\end{tabular}


Figure 3. Risk of bias presented as the percentage of studies with low risk, some concerns, or high risk, scored for the different domains of bias.

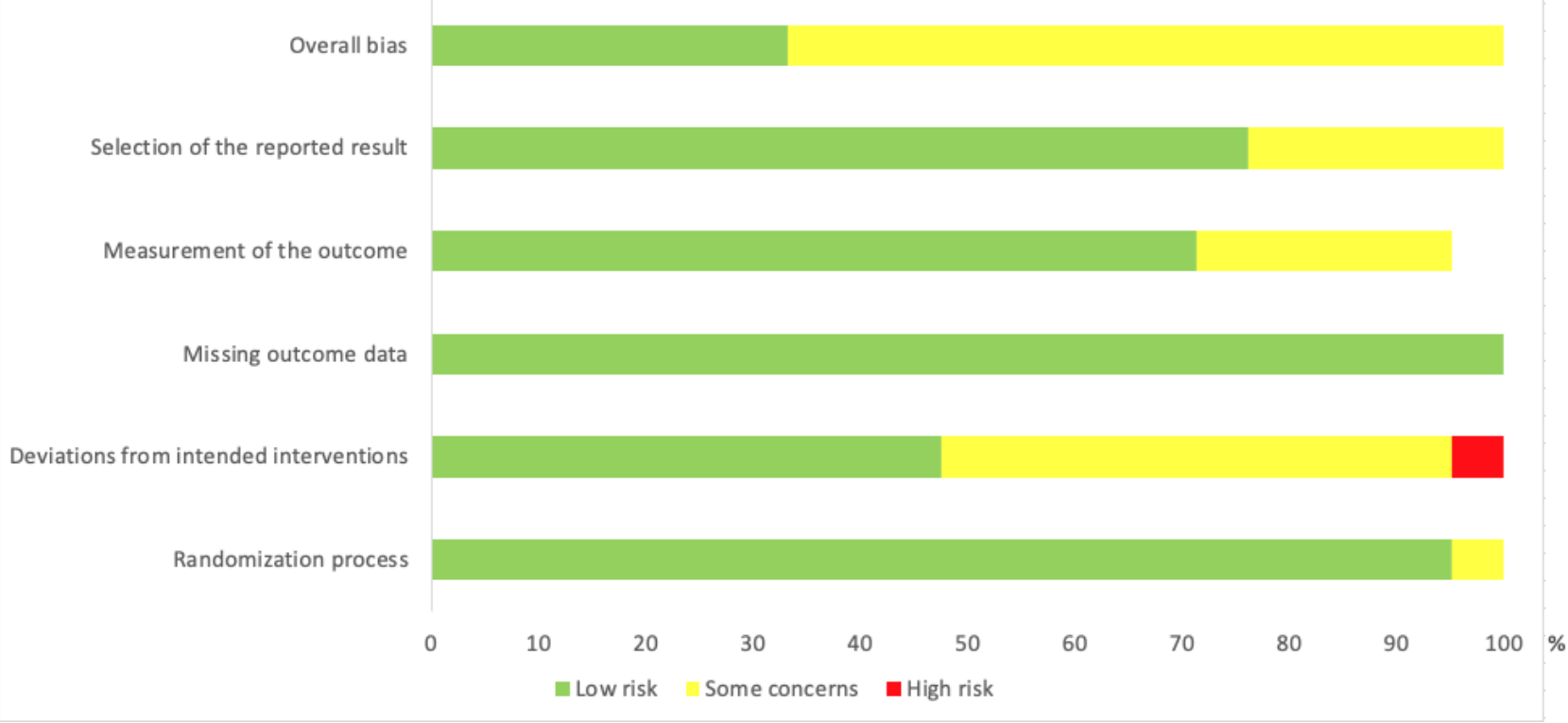

\section{Outcomes}

\section{Overview}

Characteristics of the included studies are presented per outcome. Per study, the effect of the intervention on the outcome is described as in favor of the intervention group, in favor of the control group, or no effect.

\section{Satisfaction}

A total of 12 RCTs [10-12,15,17-19,21,22,25,28], in which 2466 patients participated, reported results related to satisfaction. Two main themes emerged from these studies: satisfaction with the information provided [10-12,17,19,21,28] and satisfaction with the overall care that was delivered [10-12,18,22,25] (see Table 3).

Regarding patients' satisfaction with the information, an effect in favor of the intervention group was demonstrated in eight out of 10 studies. Interventions included an app that was used to educate patients about the preparation for their colonoscopy [28], consultation with an orthopedic surgeon [12], postoperative self-management after knee replacement surgery [10], breast cancer screening [21], healthy lifestyle interventions in myocardial infarction patients [17], and return to normal activities after abdominal surgery [11]. One study, which focused on enhanced recovery education after colorectal surgery [19], showed no difference in terms of satisfaction between the intervention and control groups. SMD ranged from medium to large in five studies [10-12,17,21] and could not be calculated for the two other studies.

Regarding patients' satisfaction with the overall care they received, an effect in favor of the intervention group was demonstrated in four out of eight studies. These studies measured the patient-perceived level of involvement by the hospital after discharge [10], satisfactory bowel preparation [22], satisfaction with anticoagulation therapy [25], level of patient-centered care in Parkinson disease [15], and overall experience with the bowel preparation process [18]. Three other studies showed no differences between groups in patients' overall satisfaction with care related to abdominal surgery [11], patients' satisfaction related to the consultation with their orthopedic surgeon [12], and patients' overall satisfaction with the recovery process after pediatric surgery [23]. SMD ranged from small to large in six studies [10-12,15,18,22,25] and could not be calculated for the other study. 
Table 3. Details about patients' satisfaction.

\begin{tabular}{|c|c|c|c|c|}
\hline Satisfaction type and study & Population (n) & Description $^{\mathrm{a}}$ & Effect $^{\mathrm{b}}$ & $\operatorname{SMD}^{\mathrm{c}}(95 \% \mathrm{CI})$ \\
\hline \multicolumn{5}{|c|}{ Satisfaction with information provided } \\
\hline Van der Meij [11] & Abdominal surgery (344) & $\begin{array}{l}\text { Personalized information on activity } \\
\text { resumption }\end{array}$ & + & $0.43(0.22$ to 0.65$)$ \\
\hline Lee $[21]$ & Breast cancer (120) & Breast cancer screening instructions & + & $0.55(0.19$ to 0.90$)$ \\
\hline Sharara [28] & Colonoscopy (160) & Bowel preparation & + & $\begin{array}{l}\text { SMD could not be calcu- } \\
\text { lated }^{\mathrm{d}}\end{array}$ \\
\hline Mata [19] & Colorectal surgery (97) & Postoperative adherence protocol & $=$ & $\begin{array}{l}\text { SMD could not be calcu- } \\
\text { lated }^{\mathrm{e}}\end{array}$ \\
\hline Timmers [10] & Knee replacement (212) & $\begin{array}{l}\text { Education on pain management, exer- } \\
\text { cises, and self-care }\end{array}$ & + & 0.97 (0.68 to 1.27$)$ \\
\hline Timmers [12] & Knee replacement (213) & $\begin{array}{l}\text { Level of knowledge about treatment } \\
\text { options }\end{array}$ & + & $0.54(0.26$ to 0.82$)$ \\
\hline Timmers [12] & Knee replacement (213) & Preparation for medical consultation & + & $0.70(0.42$ to 0.98$)$ \\
\hline Johnston [17] & Myocardial infarction (174) & Overall satisfaction with the app & + & $0.56(0.23$ to 0.88$)$ \\
\hline \multicolumn{5}{|c|}{ Satisfaction with care received } \\
\hline Van der Meij [11] & Abdominal surgery (344) & Overall satisfaction with care received & $=$ & $0.20(-0.01$ to 0.41$)$ \\
\hline Guo [25] & Atrial fibrillation (209) & Overall satisfaction with care received & + & $0.58(0.15$ to 1.00$)$ \\
\hline Wang [22] & Colonoscopy (392) & Colonoscopy treatment itself & + & $\begin{array}{l}\text { SMD could not be calcu- } \\
\text { lated }^{\mathrm{f}}\end{array}$ \\
\hline Lorenzo-Zuniga [18] & Colonoscopy (260) & Overall satisfaction with care received & + & $0.78(0.52$ to 1.04$)$ \\
\hline Timmers [10] & Knee replacement (212) & Hospital involvement during recovery & + & $0.89(0.60$ to 1.19$)$ \\
\hline Timmers [12] & Knee replacement (213) & $\begin{array}{l}\text { Medical consultation with orthopedic } \\
\text { surgeon }\end{array}$ & $=$ & $0.29(-0.02$ to 0.58$)$ \\
\hline Lakshminarayana [15] & Parkinson disease (158) & $\begin{array}{l}\text { Overall satisfaction with care received } \\
\text { (Patient-Centered Outcomes Question- } \\
\text { naire for Parkinson's Disease) }\end{array}$ & + & 0.35 (0.03 to 0.67$)$ \\
\hline Li [23] & Surgery (127) & Overall quality of recovery & $=$ & $0.20(-0.15$ to 0.55$)$ \\
\hline
\end{tabular}

${ }^{\mathrm{a}}$ All items were patient reported versus clinician reported.

${ }^{b}$ Effects were in favor of the intervention group (+) or there were no effects (=). No study had effects in favor of the control group (-).

${ }^{\mathrm{c}} \mathrm{SMD}$ : standardized mean difference.

${ }^{\mathrm{d}}$ Outcome only measured in intervention group.

${ }^{\mathrm{e}}$ No SD available (only average and $P$ value).

${ }^{\mathrm{f}}$ Nonnormal distributed data.

\section{Adherence}

A total of 11 RCTs [9,15,17-19,22,24-28], in which 2573 patients participated, reported results related to adherence. Two main themes emerged from these studies: adherence to treatment instructions $[9,18,19,22,24,26-28]$ and adherence to medication usage $[15,17,25]$ (see Table 4).

Regarding patients' adherence to treatment instructions, an effect in favor of the intervention group was demonstrated in five out of eight studies, focusing on patients' self-management in diabetes mellitus [27], hypertension [26], and adherence to purgative and dietary instructions for bowel preparation before their colonoscopy $[9,22,24]$. No differences between groups were reported in two other studies focusing on preparation for colonoscopy $[18,28]$ and a postoperative recovery program after colorectal surgery [19]. SMD ranged from small to large in six studies [9,18,24,26-28], was negative in one study [19], and could not be calculated for the other study.

Regarding patients' adherence to their medication usage, an effect in favor of the intervention group was demonstrated in all three studies addressing this theme. These studies focused on drug adherence in Parkinson disease [15], anticoagulation adherence in patients who suffered from atrial fibrillation [25], or myocardial infarction [17]. With regard to the latter, patients in the intervention group reported lower missed medication doses. However, the same study also reported that there were no differences between groups in results related to the medication adherence questionnaire that was assessed. SMD ranged from small to medium in two studies $[15,17]$ and could not be calculated for the other study. 
Table 4. Details about patients' adherence.

\begin{tabular}{|c|c|c|c|c|}
\hline Adherence type and study & Population (n) & Description $^{\mathrm{a}}$ & Effect $^{\mathrm{b}}$ & $\operatorname{SMD}^{\mathrm{c}}(95 \% \mathrm{CI})$ \\
\hline \multicolumn{5}{|l|}{ Adherence to instructions } \\
\hline Wang [22] & Colonoscopy (392) & $\begin{array}{l}\text { Purgative and dietary instructions for bowel } \\
\text { preparation }(\mathrm{CR})\end{array}$ & + & $\begin{array}{l}\text { SMD could not be } \\
\text { calculated }^{\text {d }}\end{array}$ \\
\hline Jeon $[24]$ & Colonoscopy (281) & $\begin{array}{l}\text { Purgative and dietary instructions for bowel } \\
\text { preparation (PR) }\end{array}$ & + & $\begin{array}{l}\text { SMD could not be } \\
\text { calculated }^{\mathrm{e}}\end{array}$ \\
\hline Jeon $[24]$ & Colonoscopy (281) & Clinical Bowel Preparation score (CR) & + & $0.28(0.05$ to 0.52$)$ \\
\hline Sharara [28] & Colonoscopy (160) & $\begin{array}{l}\text { Purgative and dietary instructions for bowel } \\
\text { preparation (PR) }\end{array}$ & $=$ & $\begin{array}{l}\text { SMD could not be } \\
\text { calculated }^{d}\end{array}$ \\
\hline Sharara [28] & Colonoscopy (160) & Clinical Bowel Preparation score (CR) & $=$ & $0.12(-0.19$ to 0.43$)$ \\
\hline Kang [9] & Colonoscopy (650) & $\begin{array}{l}\text { Purgative and dietary instructions for bowel } \\
\text { preparation }(\mathrm{CR})\end{array}$ & + & $0.51(0.37$ to 0.66$)$ \\
\hline Lorenzo-Zuniga [18] & Colonoscopy (260) & $\begin{array}{l}\text { Purgative and dietary instructions for bowel } \\
\text { preparation }(\mathrm{CR})\end{array}$ & $=$ & $0.16(-0.08$ to 0.42$)$ \\
\hline Mata [19] & $\begin{array}{l}\text { Colorectal surgery } \\
(97)\end{array}$ & $\begin{array}{l}\text { Postoperative recovery elements (eg, mobilization) } \\
\text { (PR) }\end{array}$ & $=$ & $-0.13(-0.52$ to 0.26$)$ \\
\hline Alanzi [27] & $\begin{array}{l}\text { Diabetes mellitus } \\
(92)\end{array}$ & Self-efficacy in diabetes mellitus & + & $0.78(0.36$ to 1.21$)$ \\
\hline Najafi Ghezeljeh [26] & Hypertension (100) & Hypertension self-management (PR) & + & $6.78(5.34$ to 8.21$)$ \\
\hline \multicolumn{5}{|l|}{ Adherence to medication } \\
\hline Lakshminarayana [15] & $\begin{array}{l}\text { Parkinson disease } \\
\text { (158) }\end{array}$ & Parkinson disease drug adherence (PR) & + & $0.37(0.05$ to 0.68$)$ \\
\hline Guo [25] & $\begin{array}{l}\text { Atrial fibrillation } \\
(209)\end{array}$ & Anticoagulation drug adherence (PR) & + & $\begin{array}{l}\text { SMD could not be } \\
\text { calculated }^{\mathrm{e}}\end{array}$ \\
\hline Johnston [17] & $\begin{array}{l}\text { Myocardial infarc- } \\
\text { tion (174) }\end{array}$ & Anticoagulation drug adherence (PR) & $=$ & $\begin{array}{l}\text { SMD could not be } \\
\text { calculated }^{\mathrm{d}}\end{array}$ \\
\hline Johnston [17] & $\begin{array}{l}\text { Myocardial infarc- } \\
\text { tion (174) }\end{array}$ & Missed medication doses (PR) & + & $0.14(-0.16$ to 0.46$)$ \\
\hline
\end{tabular}

${ }^{\mathrm{a}}$ Items were either clinician reported (CR) or patient reported (PR).

${ }^{b}$ Effects were in favor of the intervention group (+) or there were no effects (=). No study had effects in favor of the control group (-).

${ }^{\mathrm{c}} \mathrm{SMD}$ : standardized mean difference.

${ }^{\mathrm{d}}$ No SD available (only average and $P$ value).

${ }^{\mathrm{e}}$ Nonnormal distributed data.

\section{Quality of Life}

Seven RCTs [10,11,15-17,20,25], in which 1300 patients participated, reported results related to quality of life (see Table 5). An effect in favor of the intervention group was demonstrated in four studies. These studies measured the effect of the intervention on quality of life at four weeks after knee replacement surgery [10], three months after starting a program for cardiac rehabilitation [20], three months after starting a program for pelvic floor muscle training [16], and three months after starting a program for enhanced self-management after atrial fibrillation [25]. Three studies did not report an effect in the intervention group at the following time points: 6 months after intermediate-grade abdominal surgery [11], 4 months after starting a self-management program in Parkinson disease [15], and 6 weeks after starting a support program on lifestyle changes and drug adherence in myocardial infarction patients [17]. SMD ranged from small to large in five studies $[10,15,20]$ and could not be calculated for two studies $[11,25]$. 
Table 5. Details about patients' quality of life.

\begin{tabular}{|c|c|c|c|c|}
\hline Study & Population (n) & Description $^{\mathrm{a}}$ & Effect $^{b}$ & $\operatorname{SMD}^{c}(95 \% \mathrm{CI})$ \\
\hline Van der Meij [11] & $\begin{array}{l}\text { Abdominal surgery } \\
\text { (344) }\end{array}$ & After abdominal surgery & $=$ & $\begin{array}{l}\text { SMD could not be calculat- } \\
\text { ed }^{\mathrm{d}}\end{array}$ \\
\hline Guo [25] & Atrial fibrillation (209) & After starting atrial fibrillation management program & + & $\begin{array}{l}\text { SMD could not be calculat- } \\
\text { ed }^{\text {d }}\end{array}$ \\
\hline Widmer [20] & $\begin{array}{l}\text { Cardiac rehabilitation } \\
(80)\end{array}$ & After starting cardiac rehabilitation & + & $3.30(2.60$ to 4.02$)$ \\
\hline Timmers [10] & Knee replacement (212) & After knee replacement surgery & + & $0.44(0.15$ to 0.72$)$ \\
\hline Johnston [17] & $\begin{array}{l}\text { Myocardial infarction } \\
\text { (174) }\end{array}$ & After starting lifestyle and drug adherence support & $=$ & $0.33(0.01$ to 0.66$)$ \\
\hline Lakshminarayana [15] & Parkinson disease (158) & After starting self-management app & $=$ & $0.18(-0.14$ to 0.49$)$ \\
\hline Asklund [16] & $\begin{array}{l}\text { Stress urinary inconti- } \\
\text { nence }(123)\end{array}$ & After starting pelvic floor muscle training & + & $0.81(0.44$ to 1.18$)$ \\
\hline
\end{tabular}

${ }^{\mathrm{a}} \mathrm{All}$ items were patient reported versus clinician reported.

${ }^{b}$ Effects were in favor of the intervention group (+) or there were no effects (=). No study had effects in favor of the control group (-).

${ }^{\mathrm{c}} \mathrm{SMD}$ : standardized mean difference.

${ }^{\mathrm{d}}$ No SD available (only average and $P$ value).

\section{Clinical Outcomes}

A total of 11 RCTs [8,10,11,13-16,20,22,24,28], in which 1783 patients participated, reported results related to clinical outcomes. Three main themes emerged from these studies: physical functioning and pain $[10,11,13,14]$, clinical values [20,22,24,28], and symptoms [8,15,16] (see Table 6).

Regarding physical functioning, an effect in favor of the intervention group was demonstrated in three out of four studies, albeit not on all outcomes. These results were related to physical functioning after abdominal surgery [11] and pain and knee function after knee replacement surgery $[10,13]$. No differences between groups were reported concerning pain and activities after abdominal surgery [11] or concerning knee function and physiotherapy assessment tests [13]. One study related to ankle function after sports-related trauma did not demonstrate a difference between groups either [14]. SMD was medium in one study [10] and could not be calculated for the other studies.
Regarding clinical values, an effect in favor of the intervention group was demonstrated in at least one of the outcomes of all four included studies. These effects were related to weight loss during cardiac rehabilitation [20] and adenoma detection during colonoscopy [22,24,28]. No differences between groups were found concerning cholesterol, glucose, and exercise capacity in cardiac rehabilitation [20]. SMD ranged from small to large in two studies $[15,16]$ and could not be calculated for the other study.

Regarding symptoms, an effect in favor of the intervention group was demonstrated in one out of three studies. These results were related to a decrease in symptom severity after using an intervention to train pelvic floor muscles in women who suffer from stress-related urinary incontinence [16]. No differences between groups were reported in nonmotor symptoms related to Parkinson disease [15] and asthma [8]. SMD ranged from small to large within one study [20] and could not be calculated for the other studies. 
Table 6. Details about clinical parameters.

\begin{tabular}{|c|c|c|}
\hline Clinical parameters and study, population, and description ${ }^{\mathrm{a}}$ & Effect $^{b}$ & $\operatorname{SMD}^{\mathrm{c}}(95 \% \mathrm{CI})$ \\
\hline \multicolumn{3}{|l|}{ Physical functioning and pain } \\
\hline \multicolumn{3}{|l|}{ Van der Meij [11] } \\
\hline \multicolumn{3}{|l|}{ Abdominal surgery $(n=344)$} \\
\hline Physical function (PR) & + & SMD could not be calculated ${ }^{\mathrm{d}}$ \\
\hline Physical activities (PR) & $=$ & SMD could not be calculated ${ }^{\mathrm{d}}$ \\
\hline Recovery (PR) & $=$ & SMD could not be calculated ${ }^{\mathrm{d}}$ \\
\hline Pain intensity (PR) & $=$ & SMD could not be calculated ${ }^{\mathrm{d}}$ \\
\hline \multicolumn{3}{|l|}{ Van Reijnen [14] } \\
\hline \multicolumn{3}{|l|}{ Ankle trauma $(\mathbf{n}=\mathbf{2 2 0})$} \\
\hline Ankle function (PR) & $=$ & SMD could not be calculated ${ }^{\mathrm{e}}$ \\
\hline \multicolumn{3}{|l|}{ Hardt [13] } \\
\hline \multicolumn{3}{|l|}{ Knee replacement (60) } \\
\hline Knee range of motion $(\mathrm{CR})$ & + & SMD could not be calculated ${ }^{\mathrm{e}}$ \\
\hline Pain at rest (PR) & $=$ & SMD could not be calculated ${ }^{\mathrm{e}}$ \\
\hline Pain in motion $(\mathrm{PR})$ & + & SMD could not be calculated ${ }^{\mathrm{e}}$ \\
\hline Knee function (PR) & $=$ & SMD could not be calculated ${ }^{\mathrm{e}}$ \\
\hline Assessment tests (CR) & $=$ & SMD could not be calculated ${ }^{\mathrm{e}}$ \\
\hline
\end{tabular}

Timmers [10]

Knee replacement $(n=212)$

Pain at rest (PR)

Pain during activity (PR)

Pain during the night (PR)

Knee function (PR)

$\begin{array}{ll}+ & 0.51(0.23 \text { to } 0.79) \\ + & 0.49(0.21 \text { to } 0.77) \\ + & 0.42(0.14 \text { to } 0.71) \\ + & 0.47(0.19 \text { to } 0.76)\end{array}$

Clinical values

Widmer [20]

Cardiac rehabilitation $(\mathbf{n}=\mathbf{8 0})$

Weight (CR)

$\begin{array}{ll}+ & 0.80(0.32 \text { to } 1.28) \\ = & 0.49(-0.07 \text { to } 0.87) \\ = & 0.05(-0.41 \text { to } 0.52) \\ = & 0.28(-0.19 \text { to } 0.74) \\ = & 0.22(-0.24 \text { to } 0.69)\end{array}$

Wang [22]

Colonoscopy $(\mathbf{n}=392)$

Adenoma detection rate (1 adenoma detected) (CR)

Adenoma detection rate ( $>1$ adenoma detected) $(\mathrm{CR})$

$=\quad$ SMD could not be calculated ${ }^{\mathrm{d}}$

$+\quad$ SMD could not be calculated ${ }^{\mathrm{d}}$

Jeon [24]

Colonoscopy $(\mathbf{n}=\mathbf{2 8 1})$

Adenoma detection rate (overall) $(\mathrm{CR})$

$+\quad$ SMD could not be calculated ${ }^{\mathrm{e}}$

Sharara [28] 


\begin{tabular}{|c|c|c|}
\hline Clinical parameters and study, population, and description ${ }^{\mathrm{a}}$ & Effect $^{\mathrm{b}}$ & $\operatorname{SMD}^{\mathrm{c}}(95 \% \mathrm{CI})$ \\
\hline \multicolumn{3}{|l|}{ Colonoscopy $(n=160)$} \\
\hline Adenoma detection rate (overall) $(\mathrm{CR})$ & + & SMD could not be calculated \\
\hline \multicolumn{3}{|l|}{ Symptoms } \\
\hline \multicolumn{3}{|l|}{ Perry $[8]$} \\
\hline \multicolumn{3}{|l|}{ Asthma $(n=34)$} \\
\hline Asthma control rest (PR) & $=$ & SMD could not be calculated ${ }^{\mathrm{e}}$ \\
\hline \multicolumn{3}{|l|}{ Lakshminarayana [15] } \\
\hline \multicolumn{3}{|l|}{ Parkinson disease $(\mathrm{n}=158)$} \\
\hline Range of nonmotor symptoms (PR) & $=$ & $0.16(-0.16$ to 0.48$)$ \\
\hline \multicolumn{3}{|l|}{ Asklund [16] } \\
\hline \multicolumn{3}{|l|}{ Stress urinary incontinence $(n=123)$} \\
\hline Symptom severity (PR) & + & $0.95(0.58$ to 1.33$)$ \\
\hline
\end{tabular}

${ }^{\mathrm{a}}$ Items were either patient reported (PR) or clinician reported (CR).

${ }^{b}$ Effects were in favor of the intervention group (+) or there were no effects (=). No study had effects in favor of the control group (-).

${ }^{\mathrm{c}} \mathrm{SMD}$ : standardized mean difference.

${ }^{\mathrm{d}}$ No SD available (only average and $P$ value).

${ }^{\mathrm{e}}$ Nonnormal distributed data.

\section{Health Care Economics}

Five RCTs $[10,11,19,23]$, in which 860 patients participated, reported results related to health care economics (see Table 7). An effect in favor of the intervention group was demonstrated in three studies, concerning patients' contact with health care providers after total knee replacement surgery [10] and after pediatric day-care surgery [23], as well as after returning to work after abdominal surgery [11]. The other studies did not report an effect in favor of the intervention group for patients undergoing colorectal or abdominal surgery $[11,19]$ or patients attending a cardiac rehabilitation program [20]. Regarding 30-day hospital readmissions, an effect in favor of the control group was demonstrated after colorectal surgery [19]. SMD ranged from small to large in two studies $[19,23]$ and could not be calculated for the other studies. 
Table 7. Details of health care economics of studies.

\begin{tabular}{|c|c|c|}
\hline Study, Population (n), Description ${ }^{\mathrm{a}}$ & Effect $^{\mathrm{b}}$ & $\operatorname{SMD}^{\mathrm{c}}(95 \% \mathrm{CI})$ \\
\hline \multicolumn{3}{|l|}{ Van der Meij [11] } \\
\hline \multicolumn{3}{|l|}{ Abdominal surgery (344) } \\
\hline Postoperative complications (CR) & $=$ & SMD could not be calculated ${ }^{\mathrm{d}}$ \\
\hline Mean cost differences (CR) & $=$ & SMD could not be calculated ${ }^{\mathrm{d}}$ \\
\hline Return to work (PR) & + & SMD could not be calculated ${ }^{\mathrm{d}}$ \\
\hline Return to $75 \%$ of normal activities (PR) & $=$ & SMD could not be calculated ${ }^{d}$ \\
\hline \multicolumn{3}{|l|}{ Widmer [20] } \\
\hline \multicolumn{3}{|l|}{ Cardiac rehabilitation $(80)$} \\
\hline Emergency department visits (CR) & $=$ & SMD could not be calculated ${ }^{\mathrm{d}}$ \\
\hline Rehospitalization (CR) & $=$ & SMD could not be calculated ${ }^{\mathrm{d}}$ \\
\hline Emergency department visits plus rehospitalization (CR) & $=$ & SMD could not be calculated ${ }^{\mathrm{d}}$ \\
\hline \multicolumn{3}{|l|}{ Mata [19] } \\
\hline \multicolumn{3}{|l|}{ Colorectal surgery $(97)$} \\
\hline Length of stay (CR) & $=$ & $0.19(-0.21$ to 0.59$)$ \\
\hline Postoperative complications (CR) & $=$ & SMD could not be calculated ${ }^{d}$ \\
\hline 30-day reoperation $(\mathrm{CR})$ & $=$ & SMD could not be calculated ${ }^{\mathrm{d}}$ \\
\hline 30-day emergency department visits (CR) & $=$ & SMD could not be calculated ${ }^{\mathrm{d}}$ \\
\hline 30-day hospital readmissions (CR) & - & SMD could not be calculated ${ }^{d}$ \\
\hline \multicolumn{3}{|l|}{ Timmers [10] } \\
\hline \multicolumn{3}{|l|}{ Knee replacement (212) } \\
\hline $\begin{array}{l}\text { Contact with hospital, general practitioner, or home care organization during the } 4 \\
\text { weeks after discharge (PR) }\end{array}$ & + & SMD could not be calculated ${ }^{d}$ \\
\hline \multicolumn{3}{|l|}{ Li [23] } \\
\hline \multicolumn{3}{|l|}{ Surgery (127) } \\
\hline Time consumed during follow-up (CR) & + & 3.58 (3.02 to 4.14$)$ \\
\hline
\end{tabular}

${ }^{\mathrm{a}}$ Items were either clinician reported (CR) or patient reported (PR).

${ }^{b}$ Effects were in favor of the intervention group (+), in favor of the control group (-), or there were no effects (=).

${ }^{\mathrm{c}} \mathrm{SMD}$ : standardized mean difference.

${ }^{\mathrm{d}}$ Nonnormal distributed data.

\section{Knowledge}

Four RCTs [10,21,25,27], in which 634 patients participated, reported results related to condition- or treatment-specific knowledge acquisition (see Table 8). An effect in favor of the intervention group was demonstrated in all four studies. All studies focused on disseminating disease-specific information, ranging from treatment options for patients with knee complaints due to osteoarthritis [12] to self-management in atrial fibrillation patients [25] or diabetes mellitus [27] and general knowledge about breast cancer and screening options [21]. SMD ranged from medium to large in three studies [12,21,27] and could not be calculated for one study. 
Table 8. Details about disease-specific knowledge acquisition.

\begin{tabular}{lllll}
\hline Study & Population (n) & Description $^{\mathrm{a}}$ & Effect $^{\mathrm{b}}$ & SMD $^{\mathrm{c}}(95 \% \mathrm{CI})$ \\
\hline Guo [25] & Atrial fibrillation (209) & Knowledge about atrial fibrillation & + & SMD could not be calculated $^{\mathrm{d}}$ \\
Lee [21] & Breast cancer (120) & Knowledge about breast cancer and screening options & + & $0.32(-0.04$ to 0.68$)$ \\
Alanzi [27] & Diabetes mellitus (92) & Knowledge about diabetes mellitus and lifestyle & + & $4.65(3.87$ to 5.44$)$ \\
Timmers [12] & Knee replacement (213) & Actual knowledge about treatment options & + & $1.27(0.95$ to 1.60$)$ \\
Timmers [12] & Knee replacement (213) & Perceived knowledge about treatment options & + & $0.87(0.56$ to 1.18$)$ \\
\hline
\end{tabular}

${ }^{\mathrm{a}} \mathrm{All}$ items were patient reported versus clinician reported.

${ }^{b}$ Effects were in favor of the intervention group (+) for all studies, versus effects in favor of the control group (-) or no effects (=).

${ }^{\mathrm{c}} \mathrm{SMD}$ : standardized mean difference.

${ }^{\mathrm{d}}$ Nonnormal distributed data.

\section{Narrative Synthesis of Overall Results}

Overall results demonstrate an average effectiveness of the intervention of 69\% (see Table 9). Satisfaction with information, adherence to instructions and medication, clinical outcomes (eg, weight loss or adenoma detection), and knowledge acquisition showed the highest effects $(>70 \%)$. When taking into account the duration of the intervention, a clear advantage in terms of effect is demonstrated by the interventions that have a duration of less than one month, compared to the interventions that take more than one month: $82 \%$ effectiveness versus $69 \%$. A clear difference is noted in the comparison between the frequencies of messaging patients with information as well: an average effectiveness of $78 \%$ in the high-frequency group (more than once per week, on average) versus $64 \%$ in the low-frequency group (once per week, on average).

Table 9. Synthesis of results: average effectiveness per outcome.

\begin{tabular}{|c|c|c|c|c|c|c|c|}
\hline \multirow[t]{2}{*}{ Outcome } & \multirow[t]{2}{*}{ Dimension } & \multirow{2}{*}{$\begin{array}{l}\text { Number of studies/ popula- } \\
\text { tion members }\end{array}$} & \multirow{2}{*}{ Average effectiveness ${ }^{\mathrm{a}}, \%$} & \multicolumn{2}{|l|}{ Duration, $\%$} & \multicolumn{2}{|c|}{ Frequency, \% } \\
\hline & & & & $\begin{array}{l}\text { Short } \\
(<1 \text { month) }\end{array}$ & $\begin{array}{l}\text { Long } \\
\text { ( } \geq 1 \text { month) }\end{array}$ & High $^{\mathrm{b}}$ & Low $^{c}$ \\
\hline Satisfaction & Information provided & $7 / 1320$ & 93 & 88 & 100 & 88 & 100 \\
\hline Satisfaction & Overall care & $8 / 1915$ & 64 & 72 & 52 & 72 & 52 \\
\hline Adherence & Instructions & $8 / 2032$ & 75 & 72 & 100 & 75 & $\mathrm{~N} / \mathrm{A}^{\mathrm{d}}$ \\
\hline Adherence & Medication usage & $3 / 541$ & 84 & N/A & 84 & 50 & 100 \\
\hline Quality of life & Overall & $7 / 1300$ & 48 & 100 & 38 & 66 & 57 \\
\hline Clinical parameters & $\begin{array}{l}\text { Physical functioning } \\
\text { and pain }\end{array}$ & $4 / 836$ & 50 & 89 & 30 & 89 & 30 \\
\hline Clinical parameters & Clinical values & $4 / 913$ & 74 & 76 & 50 & 76 & 50 \\
\hline Clinical parameters & Symptoms & $3 / 315$ & 39 & N/A & 39 & 100 & 0 \\
\hline $\begin{array}{l}\text { Health care eco- } \\
\text { nomics }\end{array}$ & Overall & $5 / 860$ & 59 & 78 & 68 & 78 & 68 \\
\hline Knowledge & Overall & $4 / 634$ & 100 & 100 & 100 & 100 & 100 \\
\hline Average effect & N/A & N/A & 69 & 82 & 69 & 78 & 64 \\
\hline
\end{tabular}

${ }^{a}$ Average effectiveness is the weighted average of the population linked to an outcome and the part of the population with a positive effect on the outcome.

${ }^{\mathrm{b}}$ High frequency is $>1$ message per week, on average.

${ }^{\mathrm{c}}$ Low frequency is $\leq 1$ message per week, on average.

${ }^{\mathrm{d}} \mathrm{N} / \mathrm{A}$ : not applicable.

\section{Discussion}

\section{Principal Findings}

The objective of this systematic review was to evaluate the effectiveness of educating patients by providing timely information using smartphone and tablet apps. In particular, we focused on patients that had undergone treatment in a hospital. A total of 21 studies were identified, most with some concerns in terms of risk of bias. Included studies showed low levels of homogeneity in terms of populations and outcomes. Overall results demonstrate an average effectiveness of the interventions in $69 \%$ of the studies. Satisfaction with information, adherence to instructions and medication, improved clinical values (eg, 
weight loss or adenoma detection), and knowledge acquisition showed the highest effects $(>70 \%)$. An overall effect of $82 \%$ was observed in studies that lasted less than one month. Studies with a higher frequency of messaging (ie, more than once per week) were associated with an average effect of $78 \%$. These results should not only be considered effective from a single outcome point-of-view, but should be, from a more holistic perspective, considered as important components required for effective patient self-management support as well [29].

Our results are in line with earlier reviews that focus on the effect of eHealth interventions on multiple outcomes in chronic health conditions [30,31]. A review by Schoeppe et al reported a positive effect in terms of prevention by focusing on lifestyle changes, such as diet, exercise, and sedentary behavior [32]. The average duration of the interventions in the Schoeppe et al review was 8 weeks, which is longer than the average duration of interventions in our review. However, this is probably due to the fact that the interventions in the Schoeppe et al review focused on behavioral changes related to lifestyle, whereas studies in our review sometimes lasted only 3 or 4 days, in which the aim is not to change one's lifestyle, but to optimize one's preparation for a one-time event such as a colonoscopy. The usage of frequent notifications has been recognized to encourage greater exposure to the intervention's content without deterring engagement [33].

Even though results seem to indicate that interventions of a short duration with a high frequency of notifications are beneficial to the patient, the low level of homogeneity across these studies makes it impossible to extract an optimal structure, duration, or frequency for messaging patients. Such a challenge has also been reported in a 2018 review on education via strategies and structures [34]. Unfortunately, only a few studies reported detailed information about the content that was provided to patients, its format (eg, text, photo, or video), and the actual timing of the content delivery. This information could have provided additional insights on what makes interventions successful or not.

Our results demonstrate the emerging character of this field of research: the 21 included studies were conducted in 10 different medical departments, covering 15 different types of treatments. Four medical specialties - cardiology, orthopedics, surgery, and gastroenterology — have had more than three studies included. Only interventions related to colonoscopy and knee replacement were studied more than once. The results regarding the number of studies that we excluded from this review also demonstrate that many studies still focus on feasibility, acceptance of technology, and the design and content of apps, rather than on the actual effect of this type of intervention.

\section{Strengths and Limitations}

To our knowledge, this review is the first to assess the effectiveness of educating patients in preparation of, during, or after their treatment in the hospital using an app for smartphones or tablets. This review adopted a detailed and comprehensive search strategy, followed by robust screening, data extraction, and risk-of-bias assessment, adhering to the PRISMA guidelines. A total of 21 studies were found eligible for inclusion, seven of them having a low risk level of bias and 14 of them having a level of bias with some concerns according to Cochrane's risk of bias assessment. The relatively large sample sizes allowed us to calculate SMDs and therewith enabled us to compare study outcomes. The observed high level of heterogeneity in terms of outcomes, population, and intervention characteristics, such as interaction models, commercial and noncommercial products, or social media platforms, made it inappropriate to perform a meta-analysis for any outcome.

In this review, we focused on the timely delivery of educational information to overcome patient-perceived information overload. The duration of the interventions within these studies ranged from 3 days to 6 months. In our opinion, this range is another indicator that this type of research is still at an early stage, in which the focus of the trial is really on the intervention itself instead of its long-term effects.

\section{Implications for Practice}

The results of our review demonstrate the effective application of smartphone and tablet apps to educate patients with timely information. The effects are visible within various outcomes and across various medical specialties. Medical practices could benefit from these effects by combining two already-existing resources: patient education materials and smartphones and tablets. Patient education is already available on hospital websites, brochures, and through the oral advice of health care professionals. Additionally, more and more patients, as well as their surrounding caretakers, possess a smartphone or tablet. By adding the concept of timing to existing educational materials, one could improve the likelihood that patients receive the right information at the right time. By using the push notification mechanism on smart devices, patients can also be actively made aware of newly available information related to their treatment. Medical practices may choose to either build an app themselves or use already-available commercial products or platforms, social media or otherwise. After the initial development of an app, little or no further adjustments to existing workflows are needed for successful implementation, which is regarded as a crucial factor for successful eHealth implementation [35]. Of course, some patients may require support during the initial downloading or configuring of the app, but when this effort is compared to the possible benefits in terms of improved outcomes, satisfaction, and health care consumption as described in this review, these efforts appear worthwhile.

\section{Future Research}

Delivering timely education to patients through an app for smartphones or tablets has the potential to contribute to the emerging field of patient education research, which may lead to a positive effect on numerous outcomes. Given the novelty of this area of research, more studies need to be performed in order to demonstrate the generalizability of the concept, as well as its long-term effects. In this review, we chose to include only RCTs, since this study design is currently considered to be the gold standard research design to assess the effectiveness of interventions. Yet, we believe it is legitimate to question whether this is the only appropriate study design, as eHealth innovations and research projects could be characterized by what we would like to refer to as "moving objects" and "moving targets." By 
moving objects, we refer to the interventions themselves, as these may easily be adapted to the real-time needs of patients and health care providers by their inventors. By moving targets, we refer to outcomes that might not have been defined in the original research protocol but arose from the data and insights that were gathered during the study. Changing the intervention itself or adding outcomes during the course of a study is, however, often considered not done, as it could quickly lead to a high risk of bias and a lower overall quality of the research. As a consequence, many interventions might not be studied at all, because from a supplier's or producer's perspective, it feels unnatural not to be able to respond to these real-world demands “just because a study design won't allow you to." This challenge was also reported by two recent studies focusing on eHealth interventions in general [36] and, more specifically, in the field of psychiatry [37].

We suggest that other study designs, such as pragmatic RCTs, action research, or even real-world data, are considered to be eligible to demonstrate the effectiveness of these interventions. These designs more closely mimic a routine clinical setting from a health care provider's perspective (ie, no double blinding or placebo-controlled setting) and allow the interventions to be altered by the supplier during the course of the study if needed. This could lower some of the existing barriers and may convince more stakeholders to participate in eHealth research.

\section{Conclusions}

This review demonstrates that educating patients with timely medical information through their smartphones or tablets improves their levels of knowledge, medication or treatment adherence, satisfaction, and clinical outcomes, as well as having a positive effect on health care economics. These effects are most pronounced in interventions with a short duration (ie, less than a month) and with a high frequency of messaging patients (ie, once per week or more). With the knowledge that patient education is a predictor for improved outcomes and the fact that patients have obvious difficulties processing large amounts of new medical information, we suggest incorporating the delivery of timely information through smartphone and tablet apps within current medical practices.

\section{Acknowledgments}

The authors would like to thank Elmie Peters, medical librarian at Radboud University Medical Center (Radboudumc), for her input in shaping and optimizing the search strategy. Furthermore, the authors would like to thank Samuel Credgington for language editing.

\section{Authors' Contributions}

All authors were involved in the design of the protocol, development of the search strategy, and selection of data sources. TT and LJ independently screened articles and assessed the risk of bias of the included studies. TT drafted the manuscript. LJ, RBK, and JAMK critically revised the manuscript. All authors read and approved the final manuscript.

\section{Conflicts of Interest}

None declared.

\section{Multimedia Appendix 1}

MEDLINE (Medical Literature Analysis and Retrieval System Online) search strategy.

[PDF File (Adobe PDF File), 43 KB-Multimedia Appendix 1]

\section{Multimedia Appendix 2}

Overview of outcomes per study and instruments used to assess them. [PDF File (Adobe PDF File), 122 KB-Multimedia Appendix 2]

\section{References}

1. Stacey D, Légaré F, Lewis K, Barry MJ, Bennett CL, Eden KB, et al. Decision aids for people facing health treatment or screening decisions. Cochrane Database Syst Rev 2017 Apr 12;4:CD001431 [FREE Full text] [doi:

10.1002/14651858.CD001431.pub5] [Medline: 28402085]

2. Dineen-Griffin S, Garcia-Cardenas V, Williams K, Benrimoj SI. Helping patients help themselves: A systematic review of self-management support strategies in primary health care practice. PLoS One 2019;14(8):e0220116 [FREE Full text] [doi: 10.1371/journal.pone.0220116] [Medline: 31369582]

3. Kessels RPC. Patients' memory for medical information. J R Soc Med 2003 May;96(5):219-222 [FREE Full text] [doi: 10.1258/jrsm.96.5.219] [Medline: 12724430]

4. Khaleel I, Wimmer BC, Peterson GM, Zaidi ST, Roehrer E, Cummings E, et al. Health information overload among health consumers: A scoping review. Patient Educ Couns 2020 Jan;103(1):15-32. [doi: 10.1016/j.pec.2019.08.008] [Medline: 31451363] 
5. Liberati A, Altman DG, Tetzlaff J, Mulrow C, Gøtzsche PC, Ioannidis JP, et al. The PRISMA statement for reporting systematic reviews and meta-analyses of studies that evaluate healthcare interventions: Explanation and elaboration. BMJ 2009 Jul 21;339:b2700 [FREE Full text] [doi: 10.1136/bmj.b2700] [Medline: 19622552]

6. Sterne JA, Savović J, Page MJ, Elbers RG, Blencowe NS, Boutron I, et al. RoB 2: A revised tool for assessing risk of bias in randomised trials. BMJ 2019 Aug 28;366:14898. [doi: 10.1136/bmj.14898] [Medline: 31462531 ]

7. Cohen J. Statistical Power Analysis for the Behavioral Sciences. 2nd edition. New York, NY: Taylor \& Francis Inc; 1988.

8. Perry TT, Marshall A, Berlinski A, Rettiganti M, Brown RH, Randle SM, et al. Smartphone-based vs paper-based asthma action plans for adolescents. Ann Allergy Asthma Immunol 2017 Mar;118(3):298-303. [doi: 10.1016/j.anai.2016.11.028] [Medline: 28111110 ]

9. Kang X, Zhao L, Leung F, Luo H, Wang L, Wu J, et al. Delivery of instructions via mobile social media app increases quality of bowel preparation. Clin Gastroenterol Hepatol 2016 Mar;14(3):429-435.e3. [doi: 10.1016/j.cgh.2015.09.038] [Medline: 26492848]

10. Timmers T, Janssen L, van der Weegen W, Das D, Marijnissen W, Hannink G, et al. The effect of an app for day-to-day postoperative care education on patients with total knee replacement: Randomized controlled trial. JMIR Mhealth Uhealth 2019 Oct 21;7(10):e15323 [FREE Full text] [doi: 10.2196/15323] [Medline: 31638594]

11. van der Meij E, Anema JR, Leclercq WK, Bongers MY, Consten EC, Schraffordt Koops SE, et al. Personalised perioperative care by e-health after intermediate-grade abdominal surgery: A multicentre, single-blind, randomised, placebo-controlled trial. Lancet 2018 Jul 07;392(10141):51-59. [doi: 10.1016/S0140-6736(18)31113-9] [Medline: 29937195]

12. Timmers T, Janssen L, Pronk Y, van der Zwaard BC, Koëter S, van Oostveen D, et al. Assessing the efficacy of an educational smartphone or tablet app with subdivided and interactive content to increase patients' medical knowledge: Randomized controlled trial. JMIR Mhealth Uhealth 2018 Dec 21;6(12):e10742 [FREE Full text] [doi: 10.2196/10742] [Medline: $\underline{30578185]}$

13. Hardt S, Schulz MR, Pfitzner T, Wassilew G, Horstmann H, Liodakis E, et al. Improved early outcome after TKA through an app-based active muscle training programme: A randomized-controlled trial. Knee Surg Sports Traumatol Arthrosc 2018 Nov;26(11):3429-3437. [doi: 10.1007/s00167-018-4918-2] [Medline: 29589050]

14. Van Reijen M, Vriend I, Zuidema V, van Mechelen W, Verhagen EA. The "Strengthen your ankle" program to prevent recurrent injuries: A randomized controlled trial aimed at long-term effectiveness. J Sci Med Sport 2017 Jun;20(6):549-554. [doi: 10.1016/j.jsams.2016.12.001] [Medline: 27988093]

15. Lakshminarayana R, Wang D, Burn D, Chaudhuri KR, Galtrey C, Guzman NV, et al. Using a smartphone-based self-management platform to support medication adherence and clinical consultation in Parkinson's disease. NPJ Parkinsons Dis 2017;3:2 [FREE Full text] [doi: 10.1038/s41531-016-0003-z] [Medline: 28649602]

16. Asklund I, Nyström E, Sjöström M, Umefjord G, Stenlund H, Samuelsson E. Mobile app for treatment of stress urinary incontinence: A randomized controlled trial. Neurourol Urodyn 2017 Jun;36(5):1369-1376. [doi: 10.1002/nau.23116] [Medline: 27611958]

17. Johnston N, Bodegard J, Jerström S, Åkesson J, Brorsson H, Alfredsson J, et al. Effects of interactive patient smartphone support app on drug adherence and lifestyle changes in myocardial infarction patients: A randomized study. Am Heart $\mathbf{J}$ 2016 Aug;178:85-94 [FREE Full text] [doi: 10.1016/j.ahj.2016.05.005] [Medline: 27502855]

18. Lorenzo-Zúñiga V, Moreno de Vega V, Marín I, Barberá M, Boix J. Improving the quality of colonoscopy bowel preparation using a smart phone application: A randomized trial. Dig Endosc 2015 Jul;27(5):590-595. [doi: 10.1111/den.12467] [Medline: 25708251]

19. Mata J, Pecorelli N, Kaneva P, Moldoveanu D, Gosselin-Tardiff A, Alhashemi M, et al. A mobile device application (app) to improve adherence to an enhanced recovery program for colorectal surgery: A randomized controlled trial. Surg Endosc $2020 \mathrm{Feb}$;34(2):742-751. [doi: 10.1007/s00464-019-06823-w] [Medline: 31087175]

20. Widmer RJ, Allison TG, Lennon R, Lopez-Jimenez F, Lerman LO, Lerman A. Digital health intervention during cardiac rehabilitation: A randomized controlled trial. Am Heart J 2017 Jun;188:65-72. [doi: 10.1016/j.ahj.2017.02.016] [Medline: 28577682]

21. Lee H, Ghebre R, Le C, Jang YJ, Sharratt M, Yee D. Mobile phone multilevel and multimedia messaging intervention for breast cancer screening: Pilot randomized controlled trial. JMIR Mhealth Uhealth 2017 Nov 07;5(11):e154 [FREE Full text] [doi: 10.2196/mhealth.7091] [Medline: 29113961]

22. Wang S, Wang Q, Yao J, Zhao S, Wang L, Li Z, et al. Effect of WeChat and short message service on bowel preparation: An endoscopist-blinded, randomized controlled trial. Eur J Gastroenterol Hepatol 2019 Feb;31(2):170-177. [doi: 10.1097/MEG.0000000000001303] [Medline: 30418256]

23. Li C, Huang S, Su X, Zhang T, Jiang K. Monitoring of home recovery using the 317-nursing mobile application following day-case surgery in children: Perspectives from both nurses and patients. Medicine (Baltimore) 2019 Aug;98(31):e16639 [FREE Full text] [doi: 10.1097/MD.0000000000016639] [Medline: 31374033]

24. Jeon SC, Kim JH, Kim SJ, Kwon HJ, Choi YJ, Jung K, et al. Effect of sending educational video clips via smartphone mobile messenger on bowel preparation before colonoscopy. Clin Endosc 2019 Jan;52(1):53-58 [FREE Full text] [doi: 10.5946/ce.2018.072] [Medline: 30153724] 
25. Guo Y, Chen Y, Lane DA, Liu L, Wang Y, Lip GY. Mobile health technology for atrial fibrillation management integrating decision support, education, and patient involvement: mAF App trial. Am J Med 2017 Dec;130(12):1388-1396.e6 [FREE Full text] [doi: 10.1016/j.amjmed.2017.07.003] [Medline: 28847546]

26. Najafi Ghezeljeh T, Sharifian S, Nasr Isfahani M, Haghani H. Comparing the effects of education using telephone follow-up and smartphone-based social networking follow-up on self-management behaviors among patients with hypertension. Contemp Nurse 2018;54(4-5):362-373. [doi: 10.1080/10376178.2018.1441730] [Medline: 29451091]

27. Alanzi T, Bah S, Alzahrani S, Alshammari S, Almunsef F. Evaluation of a mobile social networking application for improving diabetes type 2 knowledge: An intervention study using WhatsApp. J Comp Eff Res 2018 Sep;7(9):891-899. [doi: 10.2217/cer-2018-0028] [Medline: 29943647]

28. Sharara AI, Chalhoub JM, Beydoun M, Shayto RH, Chehab H, Harb AH, et al. A customized mobile application in colonoscopy preparation: A randomized controlled trial. Clin Transl Gastroenterol 2017 Jan 05;8(1):e211 [FREE Full text] [doi: 10.1038/ctg.2016.65] [Medline: 28055031]

29. Grady PA, Gough LL. Self-management: A comprehensive approach to management of chronic conditions. Am J Public Health 2014 Aug;104(8):e25-e31. [doi: 10.2105/AJPH.2014.302041] [Medline: 24922170]

30. Badawy SM, Kuhns LM. Texting and mobile phone app interventions for improving adherence to preventive behavior in adolescents: A systematic review. JMIR Mhealth Uhealth 2017 Apr 19;5(4):e50 [FREE Full text] [doi: 10.2196/mhealth.6837] [Medline: 28428157]

31. Whitehead L, Seaton P. The effectiveness of self-management mobile phone and tablet apps in long-term condition management: A systematic review. J Med Internet Res 2016 May 16;18(5):e97 [FREE Full text] [doi: 10.2196/jmir.4883] [Medline: 27185295]

32. Schoeppe S, Alley S, Van Lippevelde W, Bray NA, Williams SL, Duncan MJ, et al. Efficacy of interventions that use apps to improve diet, physical activity and sedentary behaviour: A systematic review. Int J Behav Nutr Phys Act 2016 Dec 07;13(1):127 [FREE Full text] [doi: 10.1186/s12966-016-0454-y] [Medline: 27927218]

33. Morrison LG, Hargood C, Pejovic V, Geraghty AW, Lloyd S, Goodman N, et al. Correction: The effect of timing and frequency of push notifications on usage of a smartphone-based stress management intervention: An exploratory trial. PLoS One 2018;13(5):e0198008 [FREE Full text] [doi: 10.1371/journal.pone.0198008] [Medline: 29787600]

34. Bashi N, Fatehi F, Fallah M, Walters D, Karunanithi M. Self-management education through mHealth: Review of strategies and structures. JMIR Mhealth Uhealth 2018 Oct 19;6(10):e10771 [FREE Full text] [doi: 10.2196/10771] [Medline: 30341042]

35. Granja C, Janssen W, Johansen MA. Factors determining the success and failure of eHealth interventions: Systematic review of the literature. J Med Internet Res 2018 May 01;20(5):e10235 [FREE Full text] [doi: 10.2196/10235] [Medline: 29716883]

36. Baker TB, Gustafson DH, Shah D. How can research keep up with eHealth? Ten strategies for increasing the timeliness and usefulness of eHealth research. J Med Internet Res 2014 Feb 19;16(2):e36 [FREE Full text] [doi: 10.2196/jmir.2925] [Medline: 24554442]

37. Tønning ML, Kessing LV, Bardram JE, Faurholt-Jepsen M. Methodological challenges in randomized controlled trials on smartphone-based treatment in psychiatry: Systematic review. J Med Internet Res 2019 Oct 27;21(10):e15362 [FREE Full text] [doi: 10.2196/15362] [Medline: 31663859]

\author{
Abbreviations \\ CINAHL: Cumulative Index to Nursing and Allied Health Literature \\ eHealth: electronic health \\ MEDLINE: Medical Literature Analysis and Retrieval System Online \\ MeSH: Medical Subject Headings \\ PRISMA: Preferred Reporting Items for Systematic Reviews and Meta-Analyses \\ Radboudumc: Radboud University Medical Center \\ RCT: randomized controlled trial \\ SMD: standardized mean difference
}

Edited by G Eysenbach; submitted 08.12.19; peer-reviewed by L Whitehead, D Reukers, MC Chang, G Dermody, C Mullens; comments
to author 15.01.20; revised version received 21.02.20; accepted 22.03.20; published 13.04.20
Please cite as:
Timmers T, Janssen L, Kool RB, Kremer JAM
Educating Patients by Providing Timely Information Using Smartphone and Tablet Apps: Systematic Review
J Med Internet Res 2020;22(4):e17342
URL: $\underline{\text { http://www.jmir.org/2020/4/e17342/ }}$
doi: $\underline{10.2196 / 17342}$
PMID: $\underline{32281936}$ 
(C)Thomas Timmers, Loes Janssen, Rudolf B Kool, Jan AM Kremer. Originally published in the Journal of Medical Internet Research (http://www.jmir.org), 13.04.2020. This is an open-access article distributed under the terms of the Creative Commons Attribution License (https://creativecommons.org/licenses/by/4.0/), which permits unrestricted use, distribution, and reproduction in any medium, provided the original work, first published in the Journal of Medical Internet Research, is properly cited. The complete bibliographic information, a link to the original publication on http://www.jmir.org/, as well as this copyright and license information must be included. 